\title{
OBITUARY
}

\section{Obituary for Mr G Ravichandran (Ravi), 1945-16 November 2008}

Spinal Cord (2009) 47, 650; doi:10.1038/sc.2009.13

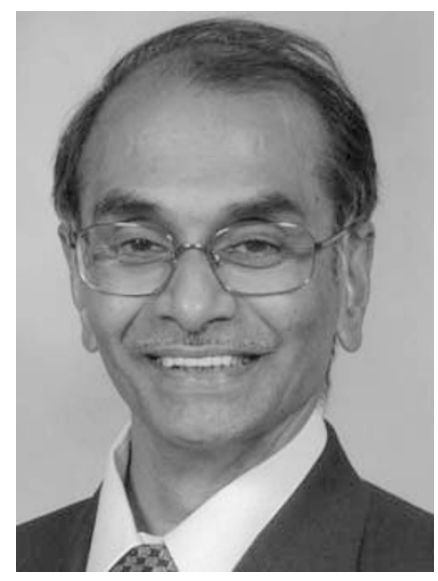

Mr Ganapathiraju Ravichandran was known as 'Ravi' by everyone who knew him. He was born in Tamil Nadu, and he obtained a degree in chemistry and a diploma in radio engineering before studying medicine in Pondicherry. After qualifying, he worked for a time in Delhi and came to England in 1972 to continue his training in orthopaedics.

During his training, Ravi developed an interest in the treatment of patients with spinal cord injury and secured a training post at the National Spinal Injuries Centre, Stoke Mandeville, UK in 1979.

He was made a Consultant in Spinal Injuries at Sheffield in 1984. The Spinal Injuries Centre was initially at Lodge Moor Hospital but was rebuilt at the Northern General Hospital in 1994.
Ravi's work with patients who had complex pressure sores made him well known not just in the field of UK spinal cord injury but in the Sheffield hospitals and throughout the region.

He had an amazing ability to read non-verbal communication. This talent made him deeply empathic and served him well in helping spinal injury patients. He believed in the biopsychosocial model of pain and in a multidisciplinary approach to its management.

Ravi's empathy also made him a great teacher, which was yet another of his loves. He would engage with those he taught to get them to look beyond the 'symptoms and signs' to the essence of the patient and their needs. In this sense, he taught truly holistic medicine, a fact that many of his students and junior doctors would later comment on and take with them in their practice.

He was loyal and supportive of his staff and, as a result, received their loyalty and affection in return. He was deeply principled and caring about his patients, many of whom will remain forever grateful for his years of dedication to his work.

He retired from the NHS in May 2007 at the age of 62, with plans to devote some of his time to further research. He barely had time to enjoy his new-found freedom before illness overtook him. He died at his home in Sheffield on Sunday 16th November 2008.

Ravi will be sadly missed by his wife and three children and by those who knew, loved, and respected him.

Martin McClelland Princess Royal Spinal Injuries Centre, Northern General Hospital, Sheffield, Yorkshire, UK E-mail: m.r.mcclelland@doctors.net.uk 